\title{
Literature review of visual representation of the results of benefit-risk assessments of medicinal products ${ }^{\dagger}$
}

Q2 Christine E. Hallgreen ${ }^{1 *}$, Shahrul Mt-Isa ${ }^{1}$, Alfons Lieftucht ${ }^{2}$, Lawrence D. Phillips ${ }^{3}$, Diana Hughes ${ }^{4}$, Susan Talbot ${ }^{5}$, Alex Asiimwe ${ }^{6}$, Gerald Downey ${ }^{5}$, Georgy Genov ${ }^{7}$, Richard Hermann ${ }^{8}$, Rebecca Noel ${ }^{9}$, Ruth Peters $^{1}$, Alain Micaleff ${ }^{10}$, Ioanna Tzoulaki ${ }^{1}$, Deborah Ashby ${ }^{1}$ and On behalf of PROTECT Benefit-Risk group

Q3 ${ }^{1}$ School of Public Health, Imperial College London, London, UK

${ }^{2}$ GlaxoSmithKline UK, Middlesex, UK

${ }^{3}$ Department of Management, London School of Economics and Political Science, London, UK

${ }^{4}$ Pfizer, New York, NY, USA

${ }^{5}$ Amgen Limited, Uxbridge, UK

${ }^{6}$ Bayer Pharma AG, Berlin, Germany

${ }^{7}$ European Medicines Agency, London, UK

${ }^{8}$ AstraZeneca LP, Wilmington, DE, USA

${ }^{9}$ Eli Lilly and Company, Lilly Corporate Center, Indianapolis, IN, USA

${ }^{10}$ MerckSerono International SA, Geneva, Switzerland

\section{ABSTRACT}

Background The PROTECT Benefit-Risk group is dedicated to research in methods for continuous benefit-risk monitoring of medicines, Q4 including the presentation of the results, with a particular emphasis on graphical methods. ${ }^{1}$

Methods A comprehensive review was performed to identify visuals used for medical risk and benefit-risk communication. The identified visual displays were grouped into visual types, and each visual type was appraised based on five criteria: intended audience, intended message, knowledge required to understand the visual, unintentional messages that may be derived from the visual and missing information that may be needed to understand the visual.

Results Sixty-six examples of visual formats were identified from the literature and classified into 14 visual types. We found that there is not one single visual format that is consistently superior to others for the communication of benefit-risk information. In addition, we found that most of the drawbacks found in the visual formats could be considered general to visual communication, although some appear more relevant to specific formats and should be considered when creating visuals for different audiences depending on the exact message to be communicated.

Conclusion We have arrived at recommendations for the use of visual displays for benefit-risk communication. The recommendation refers to the creation of visuals. We outline four criteria to determine audience-visual compatibility and consider these to be a key task in creating any visual. Next we propose specific visual formats of interest, to be explored further for their ability to address nine different types of benefit-risk analysis information. Copyright (c) 2015 John Wiley \& Sons, Ltd.

KEY WORDS—review; benefit-risk; decision-making; medicines; communication; visual representation; pharmacoepidemiology

Received 8 February 2015; Revised 8 August 2015; Accepted 27 August 2015

\section{BACKGROUND}

\footnotetext{
*Correspondence to: C. E. Hallgreen, Imperial Clinical Trial Unit, School of Public Health, Imperial College London, St Mary's Campus, Norfolk Place, Paddington, London W2 1PG, UK. Email: c.hallgreen@imperial.ac.uk

'The contents of this paper have previously been presented at various scientific conferences, and a preliminary full report of this review has also been published online on the project website http://www.imi-protect.eu/.
}

This review was carried out as part the Innovative Medicine Initiative Pharmacoepidemiological Research on Outcomes of Therapeutics by a European Consortium (PROTECT) project work package 5 benefit-risk integration and representation (PROTECT BR group). PROTECT BR group is dedicated to research in methods for continuous benefit-risk (BR) monitoring of medicines, 
including both the underpinning modelling and the presentation of the results, with a particular emphasis on graphical methods. ${ }^{1}$ This literature review of visual representation and visual/graphical formats for BR communication followed a review of methods for medicinal BR assessment $^{2}$; both were used to provide input to the PROTECT BR group case studies exploring the utility of BR methods and visual formats for communication in connection with BR assessment.

When communicating about BR, it is important to be aware that we distinguish between efficacy and safety data on the one hand and benefit and risk on the other, requiring interpretation of the efficacy and safety data for their clinical and therapeutic relevance. Benefits are defined as favourable effects and risks as unfavourable effects, separate from the uncertainty of experiencing the effects. ${ }^{3}$

Visual representation of BR information for decision-making of medicinal products is not completely exclusive to PROTECT BR group. We gained insight from other resources as a starting point for this review, including the recent BR Methodology Project commissioned by the European Medicines Agency (EMA) and the US Food and Drug Administration commissioned study to investigate the value of adding quantitative summaries of benefits and risks in standardised formats including visual displays and numerical formats. ${ }^{4}$ More general initiatives on visual representation of data and communication by special interest groups and individuals are available on the Internet. $^{5-14}$

The aim of this review is to evaluate the usefulness of different visual types for the representation and communication of BR assessment information.

\section{METHOD}

\section{Literature search strategy}

We conducted a comprehensive review of the literature and searched for articles on BR communication and visual formats for risk communication, published after the year 2000 on Scopus up until February 2014, PubMed, Web of Science and PsycINFO (for Q5 details of search terms, see Supporting Information). The reference list of articles that met our inclusion criteria was screened for relevant publications. In addition, we included related materials that were known to us at the time from the PROTECT BR group case studies, other initiatives, scientific conferences and websites on the Internet.

One reviewer (C.E.H.) examined titles and abstracts of identified articles. Relevant articles were obtained in full and assessed against the inclusion criteria described in the following.

Furthermore, we identified visual formats linked to BR assessment methodologies from a recent review ${ }^{2}$ and highlight prominent visual formats associated with each method.

\section{Inclusion criteria and data extraction}

First screening included articles if title or abstract referred to communication, presenting information on risk, efficacy or safety data or BR and/or graphical representation/information. In the following, full text screening articles were included that present or discuss one or more visual formats to communicate benefit or risk information or information in connection to BR assessment. From each relevant article, examples of the visual formats presented or discussed were extracted and also any relevant discussion and comment on the strengths and weaknesses of the visual format.

\section{Appraisal criteria and strategy}

The authors C.E.H., S.M. and A.L. identified distinct visual formats from the literature and grouped them into visual types, such as, but not limited to, bar charts, pie charts or line graphs. The visual types were appraised at group level initially. We made some comments on special cases or variation of the visual types where necessary.

The authors C.E.H., S. M. and A.L. appraised each group of visual type against five criteria: intended audience, intended message, knowledge required to understand the visuals, unintentional message that may be associated with the visuals and any missing information from the visuals that may be needed to understand them (for appraisal criteria description, see Table 7 or Supporting Information). We then consolidated that appraisals discussed and resolved any conflicts with the study team through emails, teleconferences and a final face-to-face meeting.

Because we were not able to formally test individual's comprehension, we approached the appraisal process theoretically based on two sets of principles for visual display design: Wickens' principles of display design ${ }^{15}$ and Cleveland's elementary perceptual tasks. ${ }^{16,17}$

We framed our recommendation of visual formats to be used in medical BR communication and representation through nine key BR questions. The key BR questions were adapted from the work of the Communities and Local Government (CLG) on visual representation 
of data in the public sector, as appeared on the CLG DataViz website. ${ }^{7}$

\section{RESULTS}

Searches identified 4855 potentially relevant articles from the scientific literature. Following title and abstract screening, more than 500 were examined in full text and of those, 55 were deemed eligible. ${ }^{16,18-71}$

Q6 Fourteen additional sources for visuals were identified including websites and reports. ${ }^{4,7-14,72-76}$ From the 55 identified articles and the 14 additional sources, we extracted 66 examples of visual formats (for details of search, see Supporting Information). In addition, we

Table 1. Overview of visual representation connected to benefit-risk methodologies

\begin{tabular}{|c|c|c|}
\hline Approach & $\begin{array}{l}\text { Visual } \\
\text { representation of } \\
\text { results }\end{array}$ & $\begin{array}{c}\text { Other visual representations of spe } \\
\text { interest }\end{array}$ \\
\hline $\begin{array}{l}\text { PrOACT- } \\
\text { URL }\end{array}$ & 'Effects' table & N/A \\
\hline $\begin{array}{l}\text { PhRMA } \\
\text { BRAT }\end{array}$ & $\begin{array}{l}\text { Table, dot/forest } \\
\text { plot, bar graph }\end{array}$ & Tree diagram to represent model. \\
\hline MCDA & $\begin{array}{l}\text { Bar graph, } \\
\text { 'difference display' }\end{array}$ & $\begin{array}{l}\text { Table for evidence data, tree diagram } \\
\text { to represent model, line graph for } \\
\text { sensitivity analysis. }\end{array}$ \\
\hline SMAA & $\begin{array}{l}\text { Bar graph, dot/ } \\
\text { forest plot }\end{array}$ & $\begin{array}{l}\text { Table for evidence data, tree diagram } \\
\text { and distribution plot to represent } \\
\text { model, line graph and scatter plot for } \\
\text { sensitivity analysis. }\end{array}$ \\
\hline BRR & $\begin{array}{l}\text { Bar graph, dot/ } \\
\text { forest plot, line } \\
\text { graph }\end{array}$ & $\begin{array}{l}\text { Scatter plot or contour plot for } \\
\text { sensitivity analysis. Tornado diagram } \\
\text { may be suitable to simplify further the } \\
\text { results. }\end{array}$ \\
\hline NNT/ & Dot/forest plot, line & Contour plot for sensitivity analysis. \\
\hline $\mathrm{NNH}$ & graph, scatter plot & $\begin{array}{l}\text { Tornado diagram may be suitable to } \\
\text { simplify further the results. }\end{array}$ \\
\hline INHB & $\begin{array}{l}\text { Line graph, scatter } \\
\text { plot }\end{array}$ & Contour plot for sensitivity analysis. \\
\hline $\begin{array}{l}\text { Impact } \\
\text { numbers }\end{array}$ & $\begin{array}{l}\text { Dot/forest plot, line } \\
\text { graph, scatter plot }\end{array}$ & $\begin{array}{l}\text { Contour plot for sensitivity analysis. } \\
\text { Tornado diagram may be suitable to } \\
\text { simplify further the results. }\end{array}$ \\
\hline QALY & $\begin{array}{l}\text { Bar graph, dot/ } \\
\text { forest plot }\end{array}$ & $\begin{array}{l}\text { Line graph or scatter plot for } \\
\text { sensitivity analysis. }\end{array}$ \\
\hline $\begin{array}{l}\text { Q- } \\
\text { TWiST }\end{array}$ & $\begin{array}{l}\text { Bar graph, dot/ } \\
\text { forest plot }\end{array}$ & $\begin{array}{l}\text { Line graph or scatter plot for } \\
\text { sensitivity analysis. }\end{array}$ \\
\hline PSM & N/A & Network graph to represent model. \\
\hline MTC & N/A & Network graph to represent model. \\
\hline DCE & Bar graph & $\begin{array}{l}\text { Line graph or scatter plot for } \\
\text { sensitivity analysis. }\end{array}$ \\
\hline
\end{tabular}

PrOACT-URL, problem, objective, alternative, consequence, trade-off, uncertainty, risk tolerance, linked decisions; PhRMA BRAT, Pharmaceutical Research and Manufacturers of America Benefit-Risk Action Team; MCDA, multi-criteria decision analysis; SMAA, stochastic multi-criteria acceptability analysis; BRR, benefit-risk ratio; INHB, incremental net health benefit; NNT/NNH, numbers needed to treat/numbers needed to harm; QALY, quality-adjusted life years; Q-TWiST, quality-adjusted time without symptoms and toxicity; PSM, probabilistic simulation method; MTC, mixed treatment comparison; DCE, discrete choice experiment. extracted additional 33 examples of visual formats associated directly with BR methodologies identified in a separate literature review of BR methodologies. ${ }^{2}$ In Table 1, the visual types that are connected to specific T1 BR assessment methodologies are presented.

The extracted visual formats were classified into 13 visual types, of which several include sub-groups of the variations with specific properties and ways of presentation (Table 2). The classifications were based on T2 the well-accepted terminologies of the visual formats from our past experience.

In Table 3, we present a selection of visual formats $\mathbf{T 3}$ that have more specific use in data representation and therefore may be more unfamiliar to lay readers. This is to give an idea of how an unfamiliar visual format might look. The examples in Table 3 include specialist visual formats aimed at general audiences, such as a value tree, a risk scale and a pictogram. These also include three variations of bar charts communicating specific information in specific structures (waterfall plot, difference display and tornado diagram) and visual formats that communicate statistical information

Table 2. Visual types and visual type sub-groups

\begin{tabular}{|c|c|c|}
\hline Visual type & Sub-group & Reference \\
\hline \multirow{4}{*}{ Area graphs } & Area graph & $16,23,38,46,58,67,76$ \\
\hline & Distributions plots & 14,67 \\
\hline & Volume graphs & 46,67 \\
\hline & Frontier graph & \\
\hline \multirow[t]{7}{*}{ Bar chart } & Simple bar chart & $16,22,23,29,35,40,46,49,50,59,62,67$ \\
\hline & Grouped bar chart & $16,24,32,40,46,50,54,59,64,66,67,63$ \\
\hline & Divided/stacked & $\begin{array}{l}16,23,25,28- \\
30,33,37,39,46,47,54,67-71,73\end{array}$ \\
\hline & bar chart & $\begin{array}{l}30,33,37,39,46,47,54,6 /-71,13 \\
72\end{array}$ \\
\hline & $\begin{array}{l}\text { Difference } \\
\text { diagram }\end{array}$ & \\
\hline & Tornado diagram & \\
\hline & Waterfall plots & \\
\hline Box plot & & $28,34,46,50,56,67$ \\
\hline $\begin{array}{l}\text { Cartoons, symbols } \\
\text { and icons }\end{array}$ & & $21,46,50,52,55,64,67,74,77$ \\
\hline \multirow[t]{2}{*}{ Dot chart } & Dot chart & $\begin{array}{l}16,28,40,46,67 \\
20,68,73,78\end{array}$ \\
\hline & Forest plot & $\begin{array}{l}20,68,73,78 \\
1622-24,28,35465054606667\end{array}$ \\
\hline \multirow[t]{2}{*}{ Line graphs } & Line graph & $16,22-24,28,35,46,50,54,60,66,67$ \\
\hline & $\begin{array}{l}\text { Frontier area } \\
\text { graph }\end{array}$ & 17 \\
\hline \multirow[t]{2}{*}{ Maps } & Statistical maps & $16,22,31,67$ \\
\hline & $\begin{array}{l}\text { Sector maps } \\
\text { (tree map) }\end{array}$ & \\
\hline \multirow[t]{2}{*}{ Pictograms } & & $18,22,23,25,30-33,35,36,40-42,44,47$ \\
\hline & & $50,52,54,57,59,60,65,67,70,71,77$ \\
\hline \multirow{3}{*}{ Pie charts } & Pie charts & $16,22,23,28,35,40,46,50,63,67,71$ \\
\hline & Nightingale rose & \\
\hline & Speedometer & 52 \\
\hline \multirow{5}{*}{$\begin{array}{l}\text { Risk scales/ladder } \\
\text { Scatter plot } \\
\text { Tables } \\
\text { Tree diagram }\end{array}$} & & $18,22,26,32,45,48,49,61,64,65$ \\
\hline & & $16,28,46,66,67$ \\
\hline & & $23,30,38,40,46,65,67$ \\
\hline & Tree diagram & $30,38,47$ \\
\hline & Value tree & 78 \\
\hline
\end{tabular}


Table 3. Examples of selected visual formats, ${ }^{\dagger}$ from the top left, the value tree, the risk scale, a pictogram, a waterfall plot, a difference display, a tornado diagram, a box plot, a dot plot and in the bottom right corner a forest plot

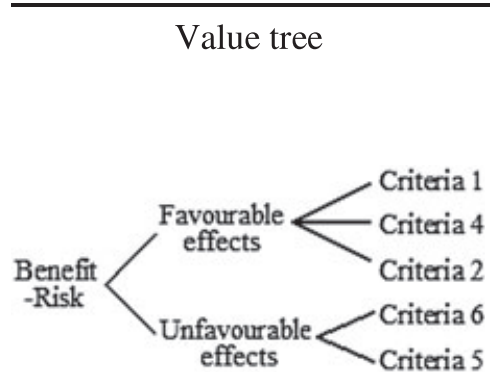

Waterfall plot (bar chart)

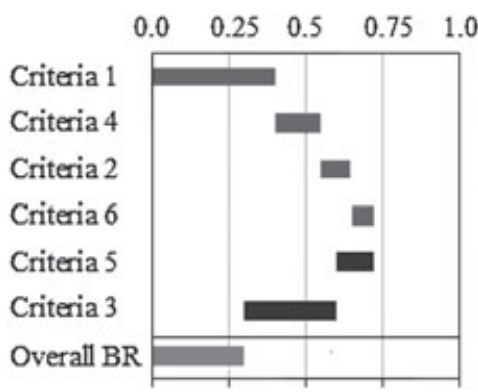

Box plot

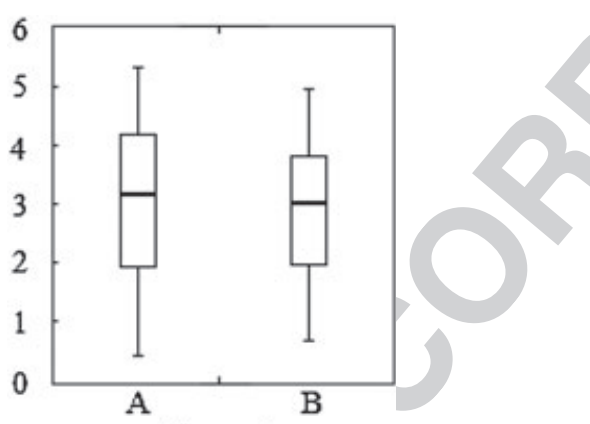

Alternative
Risk scale

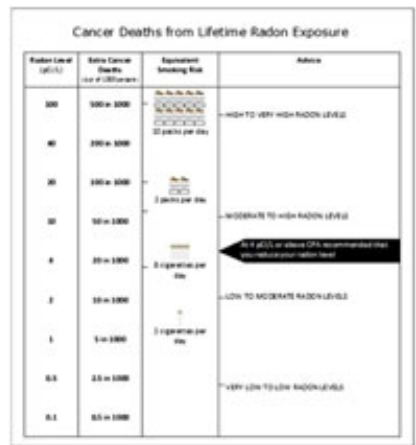

Difference display (bar chart)

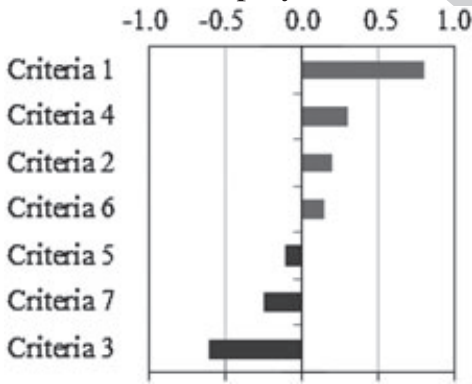

Dot plot

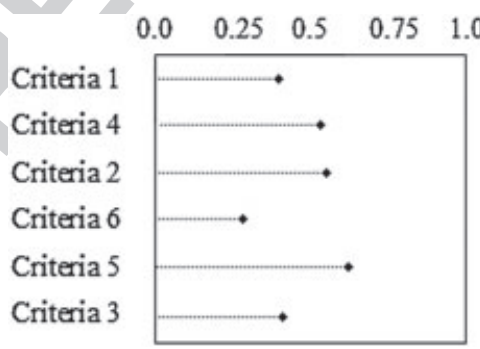

Pictogram

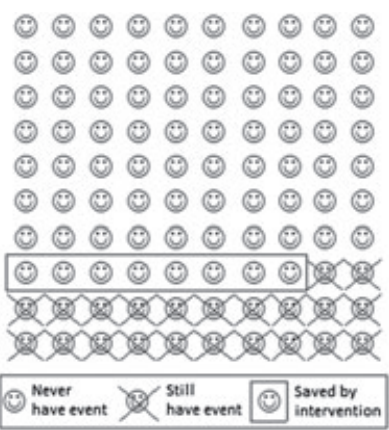

Tornado diagram (bar chart) Benefit-risk

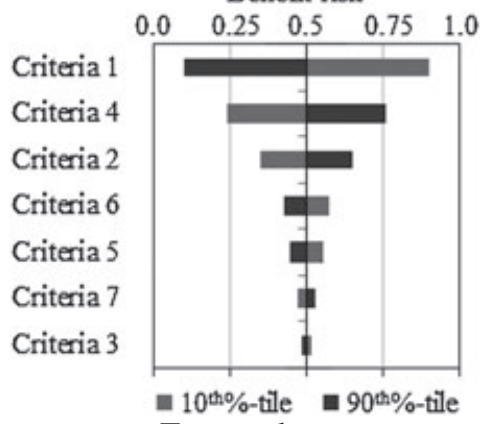

Forest plot

Risk difference

Favour A Favour B

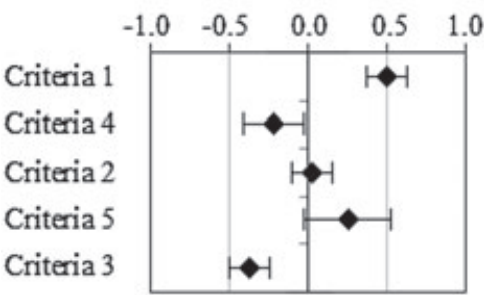

Note: For example, the criteria could be favourable clinical events such as improvement in cholesterol levels or reduced disease progression, and/or unfavourable outcomes such as increased risk of diarrhoea, psychiatric disorders or cardiovascular disorders. Alternatives A and B on these visuals may refer

Q7 to alternative treatments such as rimonabant and placebo for weight loss.

${ }^{\dagger}$ For more examples, see Supporting Information or www.imi-protect.eu/benefit-risk.

such as the box plot and forest plot. A dot plot is also shown, which is a part of a forest plot (middle part to show the values of any point estimates). The forest plot is sometimes referred to as a 'range' graph.

To facilitate the recommendations from this review, we adapted the CLG DataViz's common questions on visual data representation in the public sector to the BR scenario. ${ }^{7}$ The nine adapted BR questions are T4 shown in Table 4.
We found that several visual formats could be used in each of the pre-specified BR questions, depending on the exact message to be communicated and to whom different visuals could be relevant. Table 5 T5 gives an overview of which visual formats have the potential to be used in connection to the common BR questions. This is shown together with the information of level of expertise that is considered to be required to interpret the visual format and how the visual formats 
Table 4. Adaptation of CLG DataViz's data exploration question to BR questions (non-chronological), the CLG question is presented in the left column and our adaptation to BR assessment in the right. The first CLG question was specified into two BR questions

CLG questions

How to compare data?

What is the distribution of an indicator variable? What are the components of an indicator variable?

What is the relationship between indicator variables?

How significant are the differences?

How to visualise qualitative data?

How to visualise categorical data?
Adaptation to BR assessment

Example (possible question to visually representing BR

\author{
results of a weight loss drug)
}

1. How do I represent the (raw) magnitudes of quantitative data such as the probabilities of events to describe data and to put them into context?

2. How do I represent the magnitude of the final BR metrics to allow easy comparison of the BR balance to be made?

3. How do I represent how the magnitude of a measure is changing against a range of another measure such as time or a range of preference values?

4. How do I visualise the distributions or uncertainty of safety and efficacy data, preferences or a BR metric?

5. How do I represent the contributions from the different criteria (components) in a BR analysis to allow better perception of the key drivers?

6. How do I represent the strength of the relationships between benefit and risk metrics, for example, to visualise many data points such as patient-level data or to visualise the extent of correlation between criteria?

7. How do I represent the degree of statistical significance in the difference between alternatives?

8. How do I represent and present qualitative data such as text descriptions meaningfully and simply to support judgement without introducing extra cognitive burden?

9. How do I represent categorical data such as groups of patients, discrete events and categorical value function without distorting the data they are presenting?
How do I represent the percentages of people who achieved a $10 \%$ weight loss and experienced diarrhoea for those taking rimonabant versus placebo?

How do I represent the overall BR score to easily compare rimonabant and placebo for weight loss?

How do I represent the relationship between the score for weight loss and preference weight?

How do I represent the viability of data for weight loss observed in different trials?

How do I show visually which of the adverse events in the $\mathrm{BR}$ analysis contributes most (or least) to the overall BR score?

How do I represent the relationship between people who achieved $10 \%$ weight loss and those who experienced diarrhoea, to visually explore whether diarrhoea and weigh loss occur together?

How do I represent to which extent rimonabant is a more preferred option compared to placebo, given the current evidence and assumptions?

How do I represent the rates of depression and diarrhoea associated with rimonabant and placebo to indicate that diarrhoea may be a more unfavourable side effect?

How do I represent the percentages of people by the level of improvement in HDL cholesterol, for example, 'improved', 'did not change', 'got worse'?

CLG, Communities and Local Government; BR, benefit-risk; HDL, high-density lipoprotein.

are ranked according to Cleveland's elementary perceptual tasks. ${ }^{16}$ For a more in-depth description of the appraisal of each visual type, see Supporting
Information or the PROTECT BR review of visual formats for the representation of BR assessment of medication Stage $2 .^{79}$

Table 5. Information on the level of expertise required for interpreting visual types, the rank of visuals according to Cleveland's elementary perceptual tasks and the visual types' ability to communicate Imessages connected to the central benefit-risk (BR) questions, as indicated by an ' $\mathrm{x}$ '

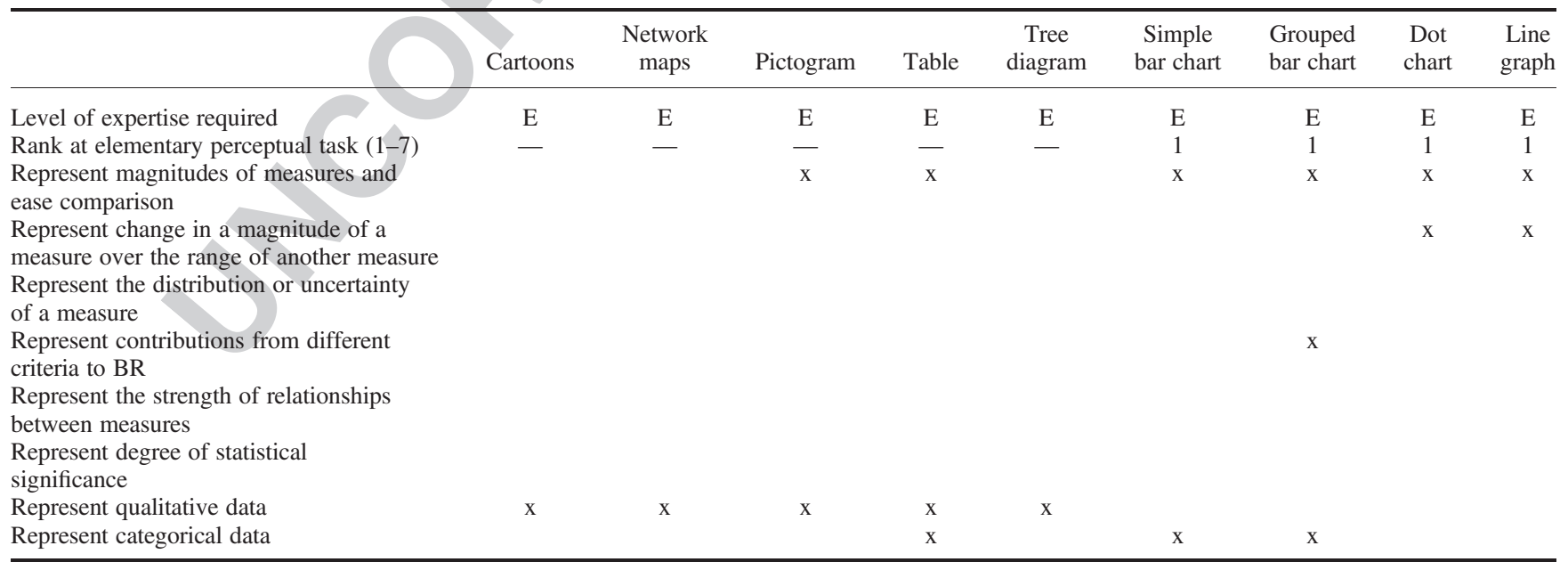

E (easy) - no or very little expertise is required of the users to understand the visuals presented. It is accessible to patients, general public and suitable for mass Q8

Q9 media communication. The visual may be presented to user without much explanation.

$\mathrm{M}$ (intermediate) - some experience with straightforward BR assessment methodology may be required of the users in is not necessary to understand the theoretical foundation of the model. It is accessible to practicing physicians and patients' representatives who need to understand and communicate BR to patients, Q10 caregivers or general public. The visuals may be presented to users without much explanation but would benefit from annotations or experts' explanation. D (difficult) - some experience and familiarity with complex BR assessment methodology, decision analysis and statistics may be required to fully exploit and understand these visuals. It is accessible to BR experts in regulatory agencies, pharmaceutical companies and academia and is suitable for specialist publication only for making high-level decisions. The visuals may also benefit from clear annotations and labelling to avoid presenting misleading information. 
Table 5. (Continued)

\begin{tabular}{|c|c|c|c|c|c|c|c|c|c|}
\hline & $\begin{array}{c}\text { Risk } \\
\text { ladder/risk } \\
\text { scale }\end{array}$ & $\begin{array}{l}\text { Area } \\
\text { graph }\end{array}$ & $\begin{array}{l}\text { Pie } \\
\text { chart }\end{array}$ & Speedometer & $\begin{array}{l}\text { Box } \\
\text { plot }\end{array}$ & $\begin{array}{l}\text { Difference } \\
\text { display }\end{array}$ & $\begin{array}{c}\text { Forest } \\
\text { plot }\end{array}$ & $\begin{array}{l}\text { Scatter } \\
\text { plot }\end{array}$ & $\begin{array}{l}\text { Statistical } \\
\text { map }\end{array}$ \\
\hline Level of expertise required & E & E & $\mathrm{E}$ & $\mathrm{E}$ & $\mathrm{M}$ & $\mathrm{M}$ & M & $\mathrm{M}$ & $\mathrm{M}$ \\
\hline Rank at elementary perceptual task (1-7) & 1 & 5 & 6 & 6 & 1 & 1 & 1 & 2 & 2 \\
\hline $\begin{array}{l}\text { Represent magnitudes of measures and } \\
\text { ease comparison }\end{array}$ & $\mathrm{x}$ & $\mathrm{x}$ & $\mathrm{x}$ & $\mathrm{x}$ & $\mathrm{X}$ & & $\mathrm{x}$ & $\mathrm{x}$ & $\mathrm{x}$ \\
\hline $\begin{array}{l}\text { Represent change in a magnitude of a } \\
\text { measure over the range of another measure }\end{array}$ & & & & & & & $\mathrm{x}$ & & \\
\hline $\begin{array}{l}\text { Represent the distribution or uncertainty } \\
\text { of a measure }\end{array}$ & & & & & & & $\mathrm{x}$ & $\mathrm{x}$ & \\
\hline $\begin{array}{l}\text { Represent contributions from different } \\
\text { criteria to BR }\end{array}$ & & & & & & $\mathrm{x}$ & & & \\
\hline $\begin{array}{l}\text { Represent the strength of relationships } \\
\text { between measures }\end{array}$ & & & & & & & & $\mathrm{x}$ & \\
\hline $\begin{array}{l}\text { Represent degree of statistical } \\
\text { significance }\end{array}$ & & & & & $\mathrm{x}$ & & $\mathrm{x}$ & & \\
\hline Represent qualitative data & & & & & & & & & \\
\hline Represent categorical data & & & & & & $\mathrm{x}$ & $\mathrm{x}$ & & \\
\hline
\end{tabular}

Table 5. (Continued)

\begin{tabular}{|c|c|c|c|c|c|c|}
\hline & $\begin{array}{c}\text { Stacked } \\
\text { bar chart }\end{array}$ & $\begin{array}{l}\text { Distribution } \\
\text { plot }\end{array}$ & $\begin{array}{l}\text { Waterfall } \\
\text { plot }\end{array}$ & $\begin{array}{l}\text { Tornado } \\
\text { diagram }\end{array}$ & $\begin{array}{c}\text { Frontier } \\
\text { graph }\end{array}$ & $\begin{array}{l}\text { Sector } \\
\text { map }\end{array}$ \\
\hline Level of expertise required & M & M & $\mathrm{D}$ & $\mathrm{D}$ & $\mathrm{D}$ & $\mathrm{D}$ \\
\hline Rank at elementary perceptual task (1-7) & 3 & 5 & 3 & 3 & 3 & 5 \\
\hline $\begin{array}{l}\text { Represent magnitudes of measures and } \\
\text { ease comparison }\end{array}$ & $\mathrm{x}$ & & & & $\mathrm{x}$ & $\mathrm{x}$ \\
\hline $\begin{array}{l}\text { Represent change in a magnitude of a } \\
\text { measure over the range of another measure }\end{array}$ & & & $\mathrm{x}$ & $\mathrm{x}$ & $\mathrm{x}$ & \\
\hline $\begin{array}{l}\text { Represent the distribution or uncertainty } \\
\text { of a measure }\end{array}$ & & $\mathrm{x}$ & & $\mathrm{x}$ & $\mathrm{x}$ & \\
\hline $\begin{array}{l}\text { Represent contributions from different } \\
\text { criteria to BR }\end{array}$ & $\mathrm{x}$ & & $\mathrm{x}$ & & & \\
\hline $\begin{array}{l}\text { Represent the strength of relationships } \\
\text { between measures }\end{array}$ & & & & $\mathrm{x}$ & & \\
\hline $\begin{array}{l}\text { Represent degree of statistical } \\
\text { significance }\end{array}$ & & $\mathrm{x}$ & & & & \\
\hline $\begin{array}{l}\text { Represent qualitative data } \\
\text { Represent categorical data }\end{array}$ & $\mathrm{x}$ & & $\mathrm{x}$ & & & \\
\hline
\end{tabular}

Effective visual representations of BR information are not only limited to pictorial representations but also include other components of the visual representation. This may result in the inclusion of words that are prone to misinterpretation or misleading. There is also a risk of potentially presenting insufficient inT6 formation. Table 6 gives an overview of some issues to be considered with visual representation of BR assessments. We also hypothesised (but have not tested) that certain visual types may easily be associated with the specific issues, based on the visual display examples extracted from the literature.

\section{DISCUSSION}

This review set out to appraise different visual types for the representation and communication of $\mathrm{BR}$ assessment information. We demonstrate that none of the visual types can be used for all purposes (Table 5), which concurs with the existing finding that there is not one single visual type that is consistently superior to others for the communication of BR information to various stakeholders. ${ }^{4}$ This is partly due to the different types of information to be presented and also partly due to the differences in an individual's perception, understanding and preference of visuals.

Firstly, we want to point out the importance of considering the intended audience for the visual communication. Some visuals such as the simpler bar charts may be used for a variety of groups from general public to trained experts, whilst others like the pictogram or the waterfall plot may have more targeted users. As for the intended audience, the intended message is a main factor in creating visuals. Although different messages 
Table 6. Overview of potential risk of misinterpretation related to visual communication

Issue

Description

Examples of visual types related to the issue

Verbal labels

Gradable adjectives

Adjectives are easy and natural to be used in the presentation of BR assessment and may better capture a person's emotions and intuitions ${ }^{25,49}$ and can have the ability to put a treatment into context. Examples of gradable adjectives are 'high risk' and 'very high risk'. Risk of misinterpretation is especially high if verbal labels are not accompanied by numerical representation. 60

Technical terms

This could be medical or statistical terms that are not understood by an untrained audience. Examples of technical terms are confidence intervals, densities, utilities and cardiovascular events.

Numerical

representation

It is important to be consistent in the use of numerical format when making comparison. ${ }^{49}$

There is a general consensus that relative frequencies are superior to percentages or probabilities for a transparent communication of risk information. ${ }^{25,33,38,49}$

Relative risk (RR)

A relative risk is a ratio of two incidence rates. RR may lead people to systematically underestimate or overestimate treatment effects, depending on the effect size. ${ }^{26,33,38}$

RR does not, on its own, provide all the necessary information to the audience because it is relative to a measurement that might be unknown to the audience. ${ }^{38}$

Denominator

neglect An example of denominator neglect is the arbitrary and inconsistent use of denominators when describing frequencies in different situations. For example, a frequency of an unfavourable effect of 1 in 5 (1:5) may be perceived as safer than a frequency of an unfavourable effect of 20 in a $100(20: 100)$, although they are exactly the same. ${ }^{25,50,54,60}$

Logarithmic scales When visuals presenting logarithmic scales are not clearly labelled, they can cause users to perceive consecutive risks as being additive rather than multiplicative, for example, reducing a probability with 1 in 10 to 1 in 100 may be perceived as being the same as reducing a probability with 1 in 100 to 1 in 1000 .

Missing part-to-

Emphasises the foreground information without sufficient background could lead to a misperception of the difference in the measures such as the probabilities between two events. $^{18}$

whole information

A long list of risks for a drug in comparison with short list of benefits, for example, may be perceived as an unfavourable benefit-risk balance without taking into account the actual quantitative data.

Risk scales

Any visual type

Any visual type

Forest plot

Pictograms

Numerical representation as

frequencies

Risk scales $^{30}$ (which are often used

for an untrained audience)

Forest plot showing relative risks or odds ratios

Bar charts

Pictograms

Dot charts

Area/volume graphs

Tables

Tree diagrams events

The right column states which visual formats are specifically related to a problem; this, however, does not mean that the problem should not be considered in connection with other visual formats.

can be communicated by a variety of visual types, the level of detail that needs to be communicated can influence the choice of visual type, for example, the stacked bar chart can be used to communicate how each of the criteria contribute to the overall BR balance, but if the contributions from several criteria are similar, it can be difficult to discriminate their individual contributions; a grouped bar chart might be a better choice. Whether the chosen visual representation causes an unintended message, or gives an unjust impression of certainty to the presented BR balance, should also be considered. Furthermore, one should consider what knowledge is required to interpret the visual, and this is often related to technical skills such as understanding the logarithmic scale or medical terms. In addition, it is also important to ensure that the visual includes all necessary information to correctly interpret and understand the visual. This could be as simple as making sure that the axes have the right labelling, or more extensively as verbally describing/explaining the visual to the users to enhance the important information.
Table 7 outlines four criteria for determining audiencevisual compatibility.

In addition to determining audience-visual compatibility when creating visuals for communication in BR assessment, we recommend applying Wickens' principles of display design ${ }^{15}$ and the GlaxoSmithKline graphics principles. ${ }^{80}$ Although these principles were not developed specifically for the visual representation of BR assessments in medicine, they do offer some advice on the design of general visual representation, which are easily adaptable for our purpose.

Despite our focus on static visual representations, the principles can also be applied to interactive/ dynamic visual representation. We acknowledge that interactive/dynamic visuals may be of great value because they enable active participation of the audience that can increase attention and perception. Through increasing, ${ }^{81}$ their use to display analysis results are still uncommon and are not substitutes for poorly designed static version of the visual display; the use and choice of colours may also effect perception 
Table 7. Criteria to determine audience-visual compatibility prior to generating visuals

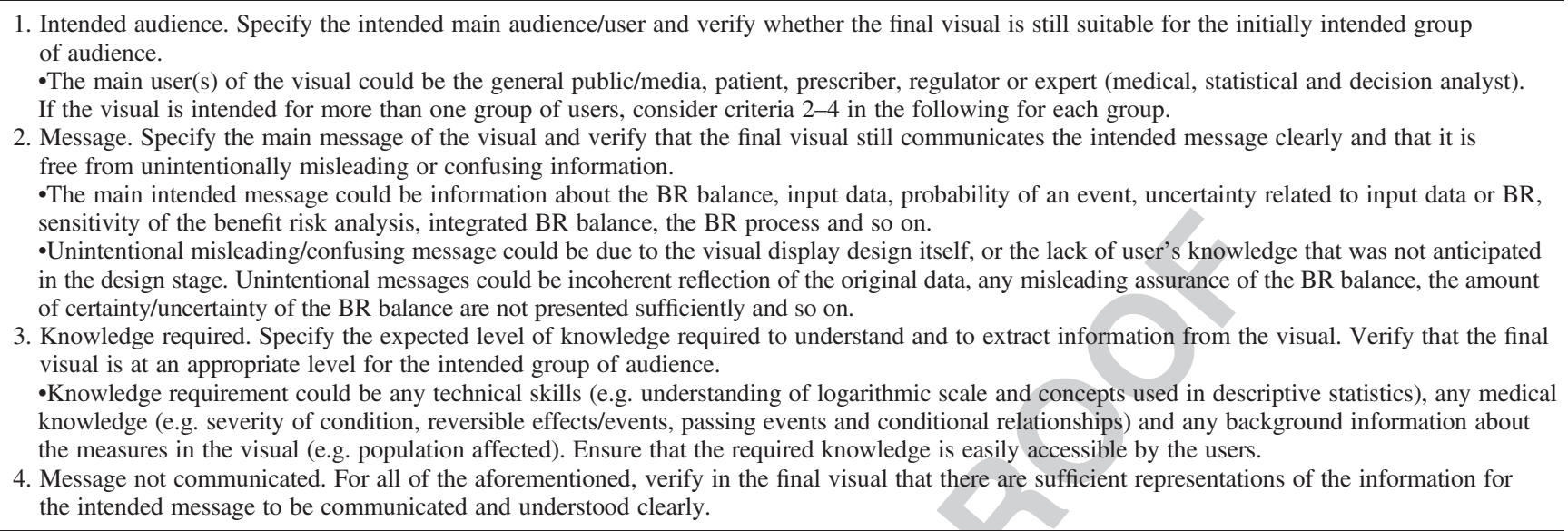

$\mathrm{BR}$, benefit-risk.

and/or comprehension. ${ }^{79}$ We did not explore colours in greater detail but recommend that users refer to other research on colours when developing their visual representations, for example, Color Brewer (http://colorbrewer2.org) and J'FLY (http://jfly.iam. u-tokyo.ac.jp/color).

We set out to propose visual types that could be of interest when presenting information related to nine central BR questions (Table 4). Here, particularly Cleveland's elementary perceptual tasks have been our focus. ${ }^{16,17}$

A table can serve as a useful BR communication tool because of its simple structure, flexibility and the ease with which it can be adapted. Readability can be enhanced through the use of colour coding to represent grouping and relationships, as carried out in the Benefit-Risk Action Team (BRAT) framework. ${ }^{82}$ For tables, it is important to be aware that they can be thought of as containing a list, with a long list of risks perceived as having unfavourable BR balance without taking into account the actual quantitative data of their severity and incidence. The table is suitable for many audiences from general public to experts. It communicates well the criteria considered in a BR assessment, their hierarchical structure and the statistical summaries associated with the favourable and unfavourable effects. The two main examples are the key BR table from BRAT $^{82}$ and the effect table from PrOACT-URL. ${ }^{72}$

Tree diagrams can communicate qualitative information, such as which benefits and risks are pivotal to the BR balance, and can represent the hierarchy of associations among the criteria, as seen with the BRAT. $^{82}$ Like the table, it is important to be aware of the potential downside that an imbalance in the number of benefit and risk criteria can be perceived as an unbalanced BR profile without taking into account the actual quantitative data.

The risk ladder/scale can facilitate comparison and judgement; it often provides information on other risks for comparison to particularly assist the general public and patients as well as regulators in perceiving the magnitude of risks under discussion. ${ }^{50}$ For the risk scale, it is important to make sure that, if used, a logarithmic scale is clearly marked and understood by the audience. Risk ladders or scales are designed to ease the communication of risks by anchoring the risks against commonly understood scenarios; however, it is important to make sure the anchors are understood and relevant to the audience.

The pictogram has generally proven to be quickly and better comprehended than other graphical formats when used to communicating individual statistics $^{35,40,65}$ and can help to prevent patients from being biased by other factors. ${ }^{33}$ Therefore, the pictogram is of interest as an easily comprehended visual format when communicating to the general public about the relative frequencies of favourable effects and the incidence of unfavourable effects.

The bar chart includes several special cases, where the simple bar chart, stacked/divided bar chart and grouped bar chart are the most familiar, the bar chart is usually easy to read and interpret. For the stacked bar chart, one should be aware that it can be more difficult to rank order the categories than for the grouped bar chart. Bar charts often best represent categorical data; they only have one value axis, whilst the other axis represents discrete categories such as groups. The simpler bar charts (simple bar chart, stacked bar chart and the grouped bar chart) could be suitable 
VISUALS FOR BENEFIT-RISK REPRESENTATION

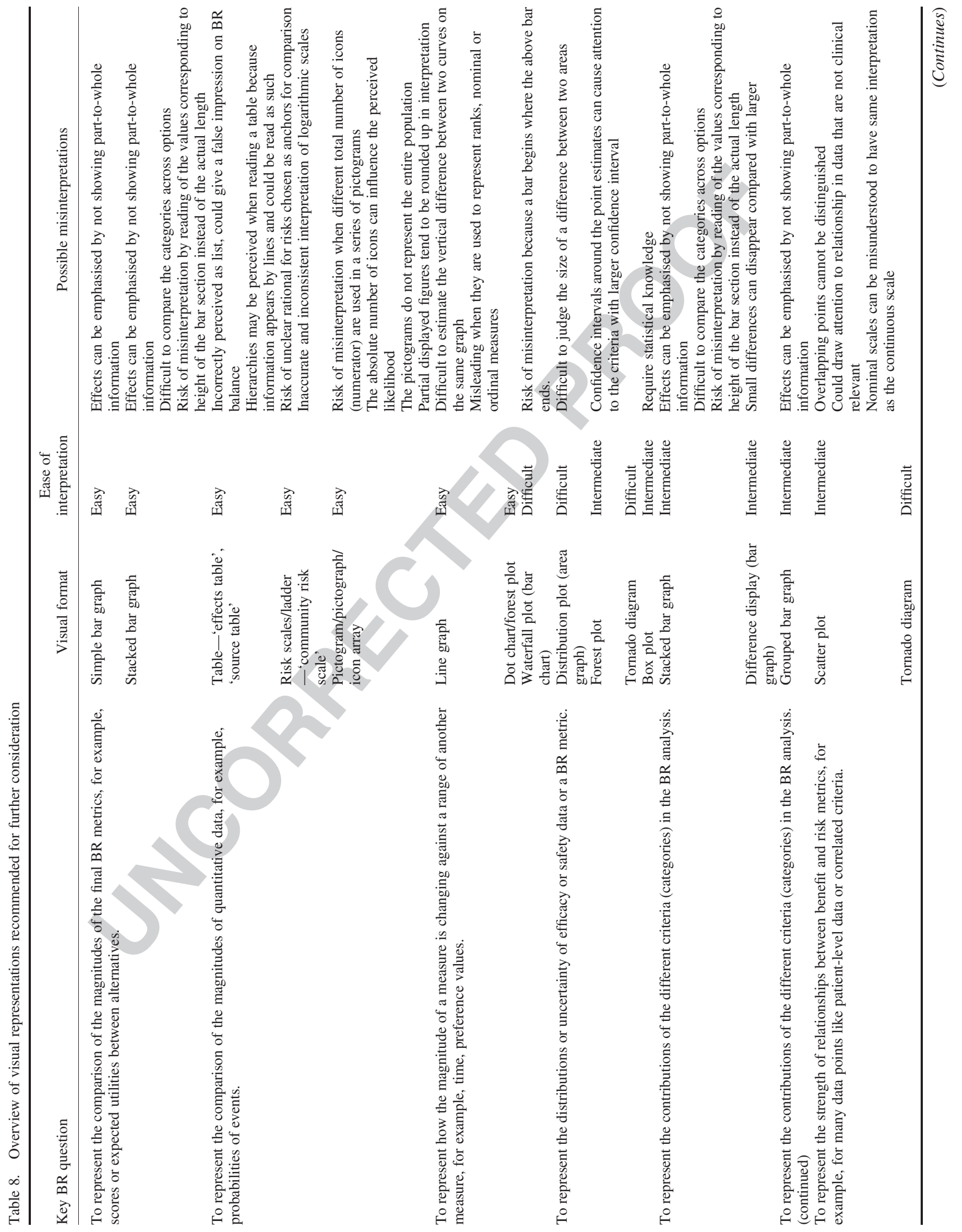

Copyright @ 2015 John Wiley \& Sons, Ltd. 
10

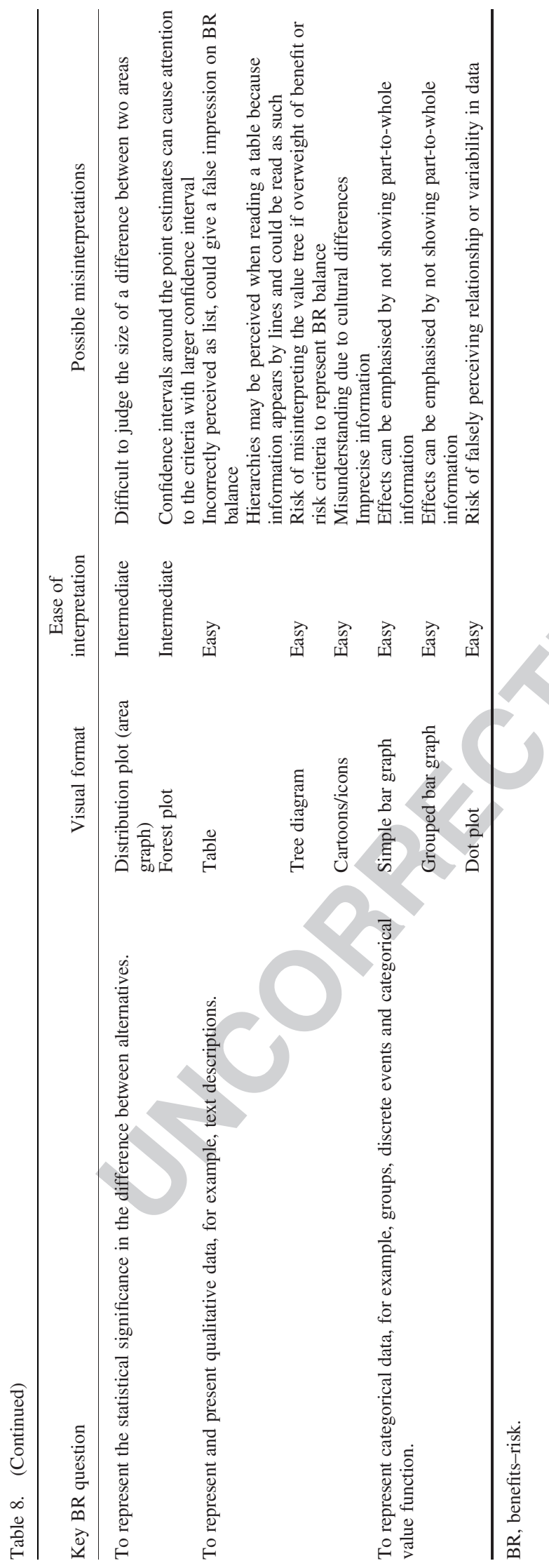

for a large variety of audiences such as the general public through the media, patients, physicians, regulators and other experts for communication about the final BR metric to visualise the contributions of the different criteria (components) in the BR analysis and categorical data. Special cases of the bar chart include the tornado diagram, the difference display and the waterfall diagram (Table 3). The special cases have many of the same features as the simpler bar charts but will generally require more explanation to be clearly understood. The difference display is relevant to represent, for a trained audience, the contributions of the different criteria in the BR analysis and was also recommended as a visual for displaying results of BR analysis in the recent report from EMA BR Methodology Project. ${ }^{72}$ The tornado diagram is Q14 proposed for the communication of uncertainty of the BR metric and visualisation of the relationships between benefit and risk metrics and correlated criteria, again for a trained audience. Finally, the waterfall plot can be used to communicate about the level of contribution each benefit and each risk provides to the overall $\mathrm{BR}$ balance.

The dot plot has similar features compared with the simple bar chart and offers a very high data-ink ratio. ${ }^{67}$ The forest plot is a special case of dot plot, which contains more statistical underpinnings, and can be used to represent summary measures such as mean risk difference and risk ratios as well as their associated uncertainty via confidence intervals, as in BRAT, $^{82}$ and is most suitable to a specialist audience such as statisticians, physicians, regulators and other experts.

Line graphs communicate the relationship of changes in one measure such as frequency or probability of an event over a range of values in another effect - time, dose levels and so on. A line graph is a very common type of visual display many people come across in various media such as in the newspaper or on television (e.g. stock values line graph and trends in historical weather or the forecast). Although general awareness may not be the best measure of broad applicability of visual understanding in BR assessment, such exposure to line graphs may make them suitable for communication to most people.

Scatter plots allow users to perceive the strength of relationship between any two uncertain quantities and can also reflect the variability in the data. Scatter plots are fairly intuitive and do not need any specialised knowledge in order to understand them.

Box plots (also known as the box and whiskers diagram) are used to convey statistical information by presenting a summary of the dataset in terms of their 
position in the data. The box plot can be used to represent the distributions of uncertainty for efficacy and safety data. Because of the technical constructions of box plot, they may be limited to experts or trained audience who have some understanding on statistical summary measures such as medians, means, quartiles and outliers.

The area graphs and volume charts suffer from people's ability to perceive area and volume differently. ${ }^{16}$ In the case of volume chart, it becomes worse because of our limitation to accurately judge the size of threedimensional objects. The only area graph we find of interest is the distribution plot, which may look like a line graph, but the information is actually being communicated by the area under the curve. The distribution plot is a well-known way of representing data distributions for experts or a trained audience who have some underQ15 standing on statistics. It can be used to represent the distribution or uncertainty of a measure, showing the patient-level distribution of data, and to communicate about the statistical significance in the difference between alternatives to an expert audience.

Cartoons/icons or pictograms can be used to indicate if something is a positive or a negative outcome, inform about specific patient groups (e.g. men or women) and indicate the direction of a change. Pictograms or cartoons have the potential to cross the language barrier and would be particularly useful for people who are sighted or partially sighted but are unable to read. It is important that pictograms, cartoons, icons or symbols used in BR visual representations are recognisable images that the intended users would have had experience seeing in the past to support their understanding. ${ }^{15}$ Cultural differences may be the most prohibitive when it comes to cartoons, icons and symbols because the images may not be common or could even be offending to some cultures.

The pie chart is an often a widely used visual; however, the reading of angles means that it scores fairly low on Cleveland's elementary perceptual task scale, and it is difficult to rank order categories and compare between pie charts. ${ }^{16}$

Statistical maps in the form of geographical maps may not be very relevant for use in the BR assessment. A different type of statistical map is the 'sector map'; it is used as a type of graphical method to detect and display differences in adverse event rates between treatment groups. The sector map provides a highlevel overview of the situation and makes use of colour to encode information that can then be drilled down to the required level of details. However, this type of representation may be affected by the limitations of area judgement and colour intensity.

\section{CONCLUSIONS}

Our main recommendation for the creation of visuals for BR assessments is to determine the compatibility between a visual and its target audience. This is carried out by considering the intended audience for the visual, the main message the visual should communicate and the knowledge required to understand and to extract information from the visual. We specifically suggest evaluating whether any message may be missed or any unintended message could be drawn from a visual.

Secondly, we aim to help BR analysis experts and decision-makers to navigate through the many visual types using a series of common BR questions. An overview of the key BR questions and the visuals proposed is provided in Table 8, together with the ease of $\mathbf{T 8}$ interpretation for each visual format and possible misinterpretation to take in consideration.

\section{DISCLAIMER}

The processes described and conclusions drawn from the work presented herein relate solely to the testing of methodologies and representations for the evaluation of benefit and risk of medicines. This report neither replaces nor is intended to replace or comment on any regulatory decisions made by national regulatory agencies or the EMA.

The views expressed in this article are the personal views of the author(s) and may not be understood or quoted as being made on behalf of or reflecting the position of the EMA or one of its committees or working parties.

\section{CONFLICT OF INTEREST}

The PROTECT Consortium has the right of commenting, but authors retain the right of accepting comments and/or suggestions. The Consortium reviewed and approved the final paper.

\section{KEY POINTS}

- There is not one single visual type that is consistently superior to others for the communication of BR information to various stakeholders.

- Creating visuals for communication in BR assessments is too important to consider the compatibility between a visual and its target audience.

- We propose a number of visual types that could be of interest when presenting information related to nine central $\mathrm{BR}$ questions. 


\section{ETHICS STATEMENT}

The authors state that no ethical approval was needed.

\section{ACKNOWLEDGEMENTS}

Q17 All persons mentioned in this acknowledgement have participated in the PROTECT BR group; participants have given written consent to be acknowledged in this paper.

The research leading to these results was conducted as part of the PROTECT Consortium (www.imi-protect. eu), which is a public-private partnership coordinated by the EMA. The PROTECT project has received support from the Innovative Medicines Initiative Joint Undertaking (www.imi.europa.eu) under grant agreement no. 115004 , resources of which are composed of financial contribution from the European Union's Seventh Framework Programme (FP7/2007-2013) and EFPIA companies' in kind contribution.

\section{AUTHOR CONTRIBUTIONS}

Q18Billy Amzal, Simon Ashworth, Johan Bring, Torbjorn Callreus, Edmond Chan, Morten Colding-Jorgensen, Christoph Dierig, Susan Duke, Adam Elmachtoub, David Gelb, Ian Hirsch, Steve Hobbiger, Kimberley Hockley, Juhaeri Juhaeri, Silvia Kuhls, Davide Luciani, Sofia Mahmud, Marilyn Metcalf, Jeremiah Mwangi, Thai Son Tong Nguyen, Richard Nixon, John Pears, George Quartey, Sinan B. Sarac, Isabelle Stoeckert, Elizabeth J. Swain, Andrew Thomson, Laurence Titeux, Hendrika A. van den Ham, Tjeerd P. van Staa, Ed Waddingham, Nan Wang, Lesley Wise. Christine E. Hallgreen was previously employed by Novo Nordisk A/S, Soeborg, Denmark, when this work started. Alex Asiimwe was previously employed by Eli Lilly, USA, when this work was started.

\section{REFERENCES}

1. Pharmacoepidemiological Research on Outcomes of Therapeutics by a European Consortium, WP5 benefit-risk integration and representation. "- [cited 2014]. Available from: http://www.imi-protect.eu/wp5.shtml.

2. Mt-Isa S, Hallgreen CE, Wang N, et al. Balancing benefit and risk of medicines: a systematic review and classification of available methodologies. Pharmacoepidemiol Drug Saf 2014; 23(7): 667-678 PubMed PMID: 24821575.

3. EMA Benefit-Risk Methodology Project Team. Work package 1 report: description of the current practice of benefit-risk assessment for centralised procedure products in the EU regulatory network. 2011 Contract No.: EMA/227124/2011.

4. Fischhoff B, Brewer NT, Downs JS. Communicating Risk and Benefits: An Evidence-based User's Guide: Food and Drug Administration (FDA); 2011 14.12.2011.

Q20 5. CTSpedia.-- [cited 2013]. Available from: https://www.ctspedia.org.

Q21 6. Drugs Box -- [cited 2013]. Available from: http://www.thedrugsbox.co.uk

7. DataViz: improving data visualisation for the public sector -• [cited 2013]. Available from: http://www.improving-visualisation.org.

8. Spiegelhalter D. Understanding Uncertainty website 2010. Available from: http://understandinguncertainty.org.

Q23 9. FlowingData [cited 2013]. Available from: http://flowingdata.com.
10. Few S. Perceptual Edge .- [cited 2013]. Available from: http://www. perceptualedge.com.

11. Tufte E. The work of Edward Tufte and Graphics Press -• [cited 2013]. Available from: http://www.edwardtufte.com/tufte.

12. McCandless D. Information is Beautiful -- [cited 2013]. Available from: http:// www.informationisbeautiful.net.

13. CIRS. Centre for Innovation in Regulatory Science website "- [cited 2013]. Available from: http://www.cirsci.org

14. Rosling H. Gapminder -• [cited 2013]. Available from: (http://www.gapminder.org).

15. Wickens CD, Lee J, Liu YD, Cordon-Becker S. An introduction to human factors engineering. 2004

16. Cleveland WS, Mcgill R. Graphical perception-theory, experimentation, and application to the development of graphical methods. J Am Stat Assoc 1984; 79(387): 531-554 PubMed PMID: WOS:A1984TK97500006. English.

17. Carswell CM. Choosing specifiers - an evaluation of the basic tasks model of graphical perception. Hum Factors 1992; 34(5): 535-554. PubMed PMID: WOS:A1992KA54500003. English.

18. Ancker JS, Senathirajah Y, Kukafka R, Starren JB. Design features of graphs in health risk communication: a systematic review. J Am Med Inform Assoc 2006; 13(6): 608-618.

19. Armstrong K, FitzGerald G, Schwartz JS, Ubel PA. Using survival curve comparisons to inform patient decision making can a practice exercise improve understanding? J Gen Intern Med 2001; 16(7): 482-485.

20. Armstrong K. Methods in comparative effectiveness research. J Clin Oncol 2012; 30(34): 4208-4214.

21. Bennett DL, Dharia CV, Ferguson KJ, Okon AE. Patient-physician communication: informed consent for imaging-guided spinal injections. JACR J Am College Radiol 2009; 6(1): 38-44.

22. Bostrom A, Anselin L, Farris J. Visualizing seismic risk and uncertainty: a review of related research. Ann N Y Acad Sci 2008; 1128: 29-40.

23. Brust-Renck PG, Royer CE, Reyna VF. Communicating Numerical Risk: Human Factors that Aid Understanding in Health Care. ": *", 2013; 235-276.

24. Brynne L, Bresell A, Sjögren N. Effective visualization of integrated knowledge and data to enable informed decisions in drug development and translational medicine. J Transl Med 2013; 11(1).

25. Burkell J. What are the chances? Evaluating risk and benefit information in consumer health materials. J Med Libr Assoc 2004; 92(2): 200-208.

26. Burkiewicz JS, Vesta KS, Hume AL. Improving effectiveness in communicating risk to patients. Consultant Pharmacist 2008; 23(1): 37-43.

27. Cleveland WS. The Elements of Graphing Data. Hobart Press: -", 1994.

28. Cleveland WS, McGill R. Graphical perception and graphical methods for analyzing scientific data. Science 1985; 229(4716): 828-833.

29. de Bruin WB, Stone ER, Gibson JM, Fischbeck PS, Shoraka MB. The effect of communication design and recipients' numeracy on responses to UXO risk. J Risk Res 2013; 16(8): 981-1004 PubMed PMID: WOS:000325913900004.

30. Dolan JG, Qian F, Veazie PJ. How well do commonly used data presentation formats support comparative effectiveness evaluations? Med Decis Making 2012; 32(6): 840-850 PubMed PMID: WOS:000311802700011. English.

31. Elmore JG, Ganschow PS, Geller BM. Communication between patients and providers and informed decision making. J Nat Canser Inst Monogr 2010; -"(41): 204-209.

32. Edwards A, Elwyn G, Mulley A. Explaining risks: turning numerical data into meaningful pictures. BMJ 2002; 324(7341): 827-830.

33. Fagerlin A, Zikmund-Fisher BJ, Ubel PA. Helping patients decide: ten steps to better risk communication. J Natl Cancer Inst 2011; 103(19): 1436-1443.

34. Fischhoff B. Communicating uncertainty fulfilling the duty to inform. Issues Sci Technol 2012; 28(4): 63-70.

35. Galesic M, Garcia-Retamero R. Graph literacy: a cross-cultural comparison. Med Decis Making 2011; 31(3): 444-457.

36. Gaissmaier W, Wegwarth O, Skopec D, Mueller A-S, Broschinski S, Politi MC Numbers can be worth a thousand pictures: individual differences in understanding graphical and numerical representations of health-related information. Health Psychol 2012; 31(3): 286-296 PubMed PMID: WOS:000303629100003.

37. Gigerenzer G, Edwards A. Simple tools for understanding risks: from innumeracy to insight. BMJ 2003; 327(7417): 741-744.

38. Gigerenzer G, Gaissmaier W, Kurz-Milcke E, Schwartz LM, Woloshin S. Helping doctors and patients make sense of health statistics. Psychological Sci Publ Interest Suppl 2008; 8(2): 53-96.

39. Goodyear-Smith F, Arroll B, Chan L, Jackson R, Wells S, Kenealy T. Patients prefer pictures to numbers to express cardiovascular benefit from treatment. Ann Fam Med 2008; 6(3): 213-217.

40. Hawley ST, Zikmund-Fisher B, Ubel P, Jancovic A, Lucas T, Fagerlin A. The impact of the format of graphical presentation on health-related knowledge and treatment choices. Patient Educ Couns 2008; 73(3): 448-455.

41. Henneman L, Oosterwijk JC, Van Asperen CJ, et al. The effectiveness of a graphical presentation in addition to a frequency format in the context of familial breast cancer risk communication: a multicenter controlled trial. BMC Med Inform Decis Mak 2013; 13(1). 
42. Hird M. A simple paper-based patient decision aid. Evid Based Med 2008; 13(6): 166-"."

43. Hollands GJ, Marteau TM. The impact of using visual images of the body within a personalized health risk assessment: an experimental study. $\mathrm{Br} J$ Health Psychol 2013; 18(2): 263-278.

44. Kasper J, Heesen C, Köpke S, Mühlhauser I, Lenz M. Why not?-communicating stochastic information by use of unsorted frequency pictograms-a randomised controlled trial. Psychosoc Med 2011; 8: Doc08-Doc.

45. Keller C, Siegrist M, Visschers V. Effect of risk ladder format on risk perception in high- and low-numerate individuals. Risk Anal 2009; 29(9): 1255-1264.

46. Kosslyn SM. Graph Design for the Eye and Mind. Oxford University Press: -•, Q39 2006

47. Kurz-Milcke E, Gigerenzer G, Martignon L. Transparency in risk communication: graphical and analog tools. Ann N Y Acad Sci 2008; 1128: 18-28.

48. Lee DH, Mehta MD. Evaluation of a visual risk communication tool: effects on knowledge and perception of blood transfusion risk. Transfusion 2003; 43(6): 779-787.

49. Lipkus IM. Numeric, verbal, and visual formats of conveying health risks: suggested best practices and future recommendations. Med Decis Making 2007; 27(5): 696-713.

50. Lipkus IM, Hollands JG. The visual communication of risk. J Natl Cancer Inst Q40 Monogr 1999; --(25): 149-163.

51. Man-Son-Hing M, O'Connor AM, Drake E, Biggs J, Hum V, Laupacis A. The effect of qualitative vs. quantitative presentation of probability estimates on patient decision-making: a randomized trial. Health Expect 2002; 5(3): 246-255.

52. Martin RW. Communicating the risk of side effects to rheumatic patients. Rheumatic Dis Clinics North Am 2012; 38(4): 653-662.

53. Norton JD. A longitudinal model and graphic for benefit-risk analysis, with case study. Drug Inf J 2011; 45(6): 741-747.

54. Okan Y, Garcia-Retamero R, Cokely ET, Maldonado A. Individual differences in graph literacy: overcoming denominator neglect in risk comprehension. $J$ Behav Decis Making 2012; 25(4): 390-401 PubMed PMID: WOS:000307165400006.

55. Politi MC, Han PKJ, Col NF. Communicating the uncertainty of harms and benefits of medical interventions. Med Decis Making 2007; 27(5): 681-695.

Q41 56. Potter K. Methods for Presenting Statistical Information: The Box Plot. ": -*, 2006.

57. Price M, Cameron R, Butow P. Communicating risk information: the influence of graphical display format on quantitative information perception-accuracy, comprehension and preferences. Patient Educ Couns 2007; 69(1-3): 121-128.

58. Rakow T. Differences in belief about likely outcomes account for differences in doctors' treatment preferences: but what accounts for the differences in belief? Qual Health Care 2001; 10(suppl. 1): i44-i49.

59. Schapira MM, Nattinger AB, McHorney CA. Frequency or probability? A qualitative study of risk communication formats used in health care. Med Decis Making 2001; 21(6): 459-467.

60. Siegel CA. Review article: explaining risks of inflammatory bowel disease therapy to patients. Aliment Pharmacol Ther 2011; 33(1): 23-32.

61. Smith AF. Discussion of risk pervades doctor-patient communication. BMJ 2002; 325(7363): 548-..

62. Sprague D, Russo JE, Lavallie DL, Buchwald DS. Influence of framing and graphic format on comprehension of risk information among American Indian tribal college students. J Cancer Educ 2012; 27(4): 752-758.

63. Spence I. No humble pie: the origins and usage of a statistical chart. $J$ Educational Behav Stat 2005; 30(4): 353-368.

64. Steiner MJ, Trussell J, Mehta N, Condon S, Subramaniam S, Bourne D. Communicating contraceptive effectiveness: a randomized controlled trial to inform a
World Health Organization family planning handbook. Am J Obstet Gynecol 2006; 195(1): 85-91.

65. Tait AR, Voepel-Lewis T, Zikmund-Fisher BJ, Fagerlin A. The effect of format on parents' understanding of the risks and benefits of clinical research: a comparison between text, tables, and graphics. J Health Commun 2010; 15(5): 487-501.

66. Tan JKH, Benbasat I. The effectiveness of graphical presentation for information extraction-a cumulative experimental approach. Decis Sci 1993; 24(1): 167-191 PubMed PMID: WOS:A1993KU50500010. English.

67. Tufte ER. The Visual Display of Quantitative Information. Graphics Press: •-, 2001. Q43

68. van Valkenhoef G, Tervonen T, Zwinkels T, de Brock B, Hillege H. ADDIS: a decision support system for evidence-based medicine. Decis Support Syst $2013 ; \mathbf{5 5}(2)$ : 459-475.

69. Waters EA, Weinstein ND, Colditz GA, Emmons K. Formats for improving risk communication in medical tradeoff decisions. J Health Commun 2006; 11(2): 167-182 PubMed PMID: 16537286 Epub 2006/03/16. eng.

70. Waters EA, Weinstein ND, Colditz GA, Emmons KM. Reducing aversion to side effects in preventive medical treatment decisions. J Exp Psychol Appl 2007; 13(1): 11-21.

71. Wilhelms EA, Reyna VF. Effective ways to communicate risk and benefit. The virtual mentor: VM 2013; 15(1): 34-41.

72. EMA Benefit-Risk Methodology Project Team. Work package 4 report: benefit-risk tools and processes. http://www.ema.europa.eu/docs/en_GB/document_library/Report/2012/03/WC500123819.pdf: EMA, 2012 EMA/297405/2012.

73. QNEXA, Vivus, Inc: hearing before the FDA Advisory Committee 2010.

74. Sibutramine, Abbot Laboratories: hearing before the FDA Advisory Committee 2010

75. Nixon R, Stoeckert I, Hodgson G, Pears J, Tzoulaki I, Montero D. Benefit-Risk Wave 1 case study report: natalizumab. London: 2013 2013 01/03/2013. Report No.: 1:b:iv.

76. Rogers S. UK plastic surgery statistics: the Guardian, 2012 [cited 2013]. Available from: http://www.theguardian.com/news/datablog/2012/jan/30/plastic-surgery-statistics-uk.

. Man-Son-Hing M, Laupacis A. Balancing the risks of stroke and upper gastrointestinal tract bleeding in older patients with atrial fibrillation. Arch Intern Med 2002; 162(5): 541-550.

78. Levitan BS, Andrews EB, Gilsenan A, et al. Application of the BRAT framework to case studies: observations and insights. Clin Pharmacol Ther 2011 Feb; 89(2): 217-224 PubMed PMID: 21178990 Epub 2010/12/24. eng.

79. Mt-Isa S, Hallgreen CE, Asiimwe A, et al. Review of visualisation methods for the representation of benefit-risk assessment of medication: Stage 2 of 2 . http:// www.imi-protect.eu/benefitsRep.shtml: 2013 15/02/2013. Report No.: 2:ii.

80. Duke S. Best practices recommendations 2012 [ cited 2013]. Available from: https://www.ctspedia.org/do/view/CTSpedia/BestPractices.

81. Buja A, Cook D, Swayne DF. Interactive high-dimensional data visualization. $J$ Comput Graph Stat 1996; 5(1): 78-99.

82. Coplan PM, Noel RA, Levitan BS, Ferguson J, Mussen F. Development of framework for enhancing the transparency, reproducibility and communication of the benefit-risk balance of medicines. Clin Pharmacol Ther 2011; 89(2): 312-315 PubMed PMID: 21160469.

\section{SUPPORTING INFORMATION}

Additional supporting information may be found in the online version of this article at the publisher's web site. 


\section{Author Query Form}

\section{Journal: Pharmacoepidemiology and Drug Safety}

\section{Article: pds_3880}

Dear Author,

During the copyediting of your paper, the following queries arose. Please respond to these by annotating your proofs with the necessary changes/additions.

- If you intend to annotate your proof electronically, please refer to the E-annotation guidelines.

- If you intend to annotate your proof by means of hard-copy mark-up, please use the standard proofing marks. If manually writing corrections on your proof and returning it by fax, do not write too close to the edge of the paper. Please remember that illegible mark-ups may delay publication.

Whether you opt for hard-copy or electronic annotation of your proofs, we recommend that you provide additional clarification of answers to queries by entering your answers on the query sheet, in addition to the text mark-up.

\begin{tabular}{|c|c|c|}
\hline Query No. & Query & Remark \\
\hline Q1 & $\begin{array}{l}\text { AUTHOR: As per journal, short title should contain }<45 \text { characters including spaces; } \\
\text { hence, the provided short title was condensed to 'Visuals for Benefit-Risk } \\
\text { Representation'. Please check the suitability of the suggested short title. }\end{array}$ & \\
\hline Q2 & $\begin{array}{l}\text { AUTHOR: Please confirm that given names (red) and surnames/family names (green) } \\
\text { have been identified correctly. }\end{array}$ & \\
\hline Q3 & AUTHOR: Please check that authors and their affiliations are correct. & \\
\hline Q4 & $\begin{array}{l}\text { AUTHOR: As per journal, Abstract should not contain reference citations. Please } \\
\text { delete the citation and reword the sentence. }\end{array}$ & \\
\hline Q5 & $\begin{array}{l}\text { AUTHOR: We conducted a comprehensive review of the literature and searched for } \\
\text { articles on BR communication and visual formats for risk communication, published } \\
\text { after the year } 2000 \text { on Scopus up until February 2014, PubMed, Web of Science and } \\
\text { PsycINFO (for details of search terms, see Supporting Information). This sentence } \\
\text { has been reworded for clarity. Please check and confirm it is correct. }\end{array}$ & \\
\hline Q6 & $\begin{array}{l}\text { AUTHOR: Fourteen additional sources for visuals were identified including websites } \\
\text { and reports. This sentence has been reworded for clarity. Please check and confirm it } \\
\text { is correct. }\end{array}$ & \\
\hline Q7 & $\begin{array}{l}\text { AUTHOR: Alternatives A and B on these visuals may refer to alternative treatments } \\
\text { such as rimonabant and placebo for weight loss. This sentence has been reworded } \\
\text { for clarity. Please check and confirm it is correct. }\end{array}$ & \\
\hline Q8 & $\begin{array}{l}\text { AUTHOR: No or very little expertise is required of the users to understand the visuals } \\
\text { presented. This sentence has been reworded for clarity. Please check and confirm it is } \\
\text { correct. }\end{array}$ & \\
\hline Q9 & $\begin{array}{l}\text { AUTHOR: It is accessible to patients, general public and suitable for mass media } \\
\text { communication. This sentence has been reworded for clarity. Please check and } \\
\text { confirm it is correct. }\end{array}$ & \\
\hline
\end{tabular}




\begin{tabular}{|c|c|c|}
\hline Query No. & Query & Remark \\
\hline Q10 & $\begin{array}{l}\text { AUTHOR:Some experience with straightforward BR assessment methodology may be } \\
\text { required of the users in is not necessary to understand the theoretical foundation of the } \\
\text { model. The meaning of this sentence is not clear; please rewrite or confirm that the } \\
\text { sentence is correct. }\end{array}$ & \\
\hline Q11 & $\begin{array}{l}\text { AUTHOR: It is accessible to BR experts in regulatory agencies, pharmaceutical } \\
\text { companies and academia and is suitable for specialist publication only for making } \\
\text { high-level decisions. This sentence has been reworded for clarity. Please check and } \\
\text { confirm it is correct. }\end{array}$ & \\
\hline Q12 & $\begin{array}{l}\text { AUTHOR: 'which in often used for an untrained audience' has been changed to } \\
\text { 'which are often used for an untrained audience' for clarity. Please check if correct. }\end{array}$ & \\
\hline Q13 & $\begin{array}{l}\text { AUTHOR: The simpler bar charts (simple bar chart, stacked bar chart and the grouped } \\
\text { bar chart) could be suitable for a large variety of audiences such as the general public } \\
\text { through the media, patients, physicians, regulators and other experts for } \\
\text { communication about the final BR metric to visualise the contributions of the } \\
\text { different criteria (components) in the BR analysis and categorical data. This sentence } \\
\text { has been reworded for clarity. Please check and confirm it is correct. }\end{array}$ & \\
\hline Q14 & $\begin{array}{l}\text { AUTHOR: The tornado diagram is proposed for the communication of uncertainty of } \\
\text { the BR metric and visualisation of the relationships between benefit and risk metrics } \\
\text { and correlated criteria, again for a trained audience. This sentence has been } \\
\text { reworded for clarity. Please check and confirm it is correct. }\end{array}$ & \\
\hline Q15 & $\begin{array}{l}\text { AUTHOR: The distribution plot is a well-known way of representing data distributions } \\
\text { for experts or a trained audience who have some understanding on statistics. This } \\
\text { sentence has been reworded for clarity. Please check and confirm it is correct. }\end{array}$ & \\
\hline Q16 & $\begin{array}{l}\text { AUTHOR: Creating visuals for communication in BR assessments is too important to } \\
\text { consider the compatibility between a visual and its target audience. This sentence has } \\
\text { been reworded for clarity. Please check and confirm it is correct. }\end{array}$ & \\
\hline Q17 & $\begin{array}{l}\text { AUTHOR: All persons mentioned in this acknowledgement have participated in the } \\
\text { PROTECT BR group; participants have given written consent to be acknowledged } \\
\text { in this paper. This sentence has been reworded for clarity. Please check and confirm } \\
\text { it is correct. }\end{array}$ & \\
\hline Q18 & $\begin{array}{l}\text { AUTHOR: Billy Amzal, Simon Ashworth, Johan Bring, Torbjorn Callreus, Edmond } \\
\text { Chan, Morten Colding-Jorgensen, Christoph Dierig, Susan Duke, Adam } \\
\text { Elmachtoub, David Gelb, Ian Hirsch, Steve Hobbiger, Kimberley Hockley, Juhaeri } \\
\text { Juhaeri, Silvia Kuhls, Davide Luciani, Sofia Mahmud, Marilyn Metcalf, Jeremiah } \\
\text { Mwangi, Thai Son Tong Nguyen, Richard Nixon, John Pears, George Quartey, } \\
\text { Sinan B. Sarac, Isabelle Stoeckert, Elizabeth J. Swain, Andrew Thomson, Laurence } \\
\text { Titeux, Hendrika A. van den Ham, Tjeerd P. van Staa, Ed Waddingham, Nan Wang, } \\
\text { Lesley Wise. The meaning of this sentence is not clear; please rewrite or confirm } \\
\text { that the sentence is correct. }\end{array}$ & \\
\hline Q19 & AUTHOR: Please provide the year of publication for Reference 1. & \\
\hline Q20 & AUTHOR: Please provide the year of publication for Reference 5. & \\
\hline Q21 & AUTHOR: Please provide the year of publication for Reference 6 . & \\
\hline Q22 & AUTHOR: Please provide the year of publication for Reference 7. & \\
\hline
\end{tabular}




\begin{tabular}{|c|c|c|}
\hline Query No. & Query & Remark \\
\hline Q23 & $\begin{array}{l}\text { AUTHOR: 'Flowing Data' has been changed to 'FlowingData'. Please check if } \\
\text { correct. }\end{array}$ & \\
\hline Q24 & AUTHOR: Please provide the year of publication for Reference 10. & \\
\hline Q25 & AUTHOR: Please provide the year of publication for Reference 11. & \\
\hline Q26 & AUTHOR: Please provide the year of publication for Reference 12. & \\
\hline Q27 & AUTHOR: Please provide the year of publication for Reference 13. & \\
\hline Q28 & AUTHOR: 'Gap Minder' has been changed to 'Gapminder'. Please check if correct. & \\
\hline Q29 & AUTHOR: Please provide the year of publication for Reference 14. & \\
\hline Q30 & AUTHOR: Please provide accessed date for Reference 15. & \\
\hline Q31 & $\begin{array}{l}\text { AUTHOR: Please provide the publisher name and the publisher location for Reference } \\
23 .\end{array}$ & \\
\hline Q32 & AUTHOR: Please provide the page range for this chapter in Reference 24. & \\
\hline Q33 & AUTHOR: Please provide the city location of the publisher for Reference 27. & \\
\hline Q34 & AUTHOR: Please provide the volume number for Reference 31. & \\
\hline Q35 & AUTHOR: Please provide the page range for this chapter in Reference 41. & \\
\hline Q36 & $\begin{array}{l}\text { AUTHOR: Please provide the page ranges for References } 42 \text { in the Reference List- } \\
\text { not just the first page. }\end{array}$ & \\
\hline Q37 & AUTHOR: Please check if Reference 44 is presented correctly. & \\
\hline Q38 & AUTHOR: Please provide the page range for this chapter in Reference 44. & \\
\hline Q39 & AUTHOR: Please provide the city location of publisher for Reference 46. & \\
\hline Q40 & AUTHOR: Please provide the volume number for this chapter in Reference 50. & \\
\hline Q41 & $\begin{array}{l}\text { AUTHOR: Please provide the publisher name and the publisher locationfor this } \\
\text { chapter in Reference } 56 .\end{array}$ & \\
\hline Q42 & $\begin{array}{l}\text { AUTHOR: Please provide the page range for Rreference } 61 \text { in the Reference List—not } \\
\text { just the first page. }\end{array}$ & \\
\hline Q43 & AUTHOR: Please provide the city location of publisher for Reference 67. & \\
\hline Q44 & AUTHOR: Please provide accessed date for Reference 73. & \\
\hline Q45 & AUTHOR: Please provide accessed date for Reference 74 . & \\
\hline
\end{tabular}


Required software to e-Annotate PDFs: Adobe Acrobat Professional or Adobe Reader (version 7.0 or above). (Note that this document uses screenshots from Adobe Reader $\mathrm{X}$ )

The latest version of Acrobat Reader can be downloaded for free at: http://get.adobe.com/uk/reader/

Once you have Acrobat Reader open on your computer, click on the Comment tab at the right of the toolbar:

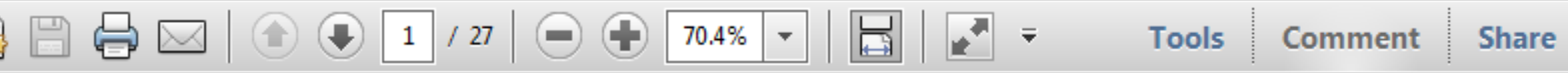

This will open up a panel down the right side of the document. The majority of tools you will use for annotating your proof will be in the Annotations section, pictured opposite. We've picked out some of these tools below:

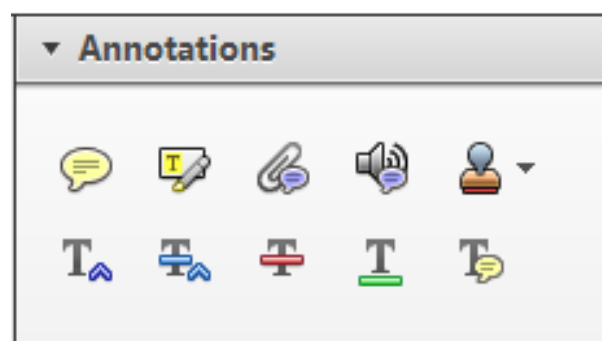

1. Replace (Ins) Tool - for replacing text.

Strikes a line through text and opens up a text box where replacement text can be entered.

How to use it

- Highlight a word or sentence.

- Click on the Replace (Ins) icon in the Annotations section.

- Type the replacement text into the blue box that appears.

Idard tramework for the analysis of $\mathrm{m}$ icy-Nevertheless, it also led to exog،

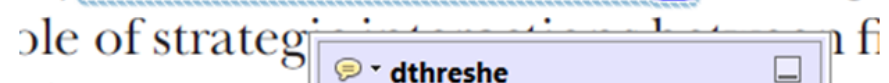
aber of comp 08/06/2011 15:58:17 is that the s1 nain compo: be level, are exc nc

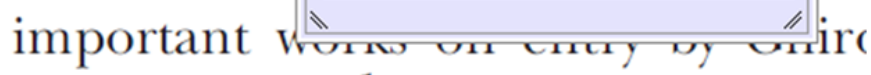
M heneferth) ${ }^{1}$ we anen the "hlarl $\mathrm{l}$

3. Add note to text Tool - for highlighting a section to be changed to bold or italic.

T Highlights text in yellow and opens up a text box where comments can be entered.

\section{How to use it}

- Highlight the relevant section of text.

- Click on the Add note to text icon in the Annotations section.

- Type instruction on what should be changed regarding the text into the yellow box that appears.

namic responses of mark ups ent with the VAR evidence

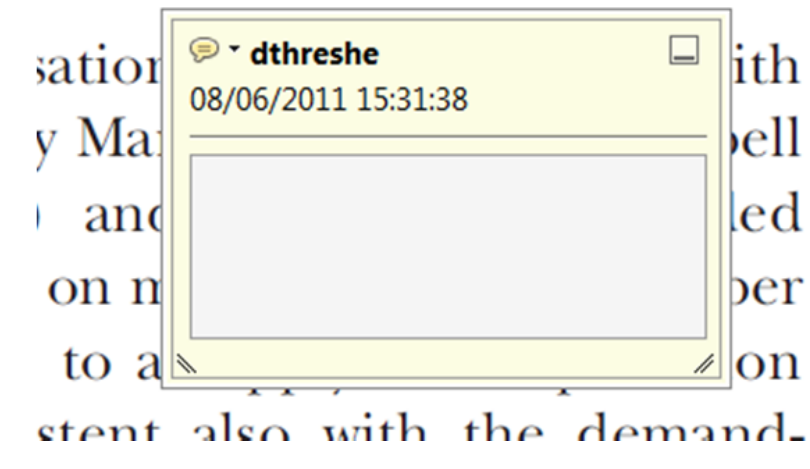

2. Strikethrough (Del) Tool - for deleting text.

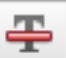

Strikes a red line through text that is to be deleted.

How to use it

- Highlight a word or sentence.

- Click on the Strikethrough (Del) icon in the Annotations section.

there is no room tor extra prohts al c ups are zero and the number of ret) values are not determined by Blanchard and Kiyotaki (1987), sfect competition in general equilil ts of aggregate demand and supply lassical framework assuming monol eph on evorenous number of firme

4. Add sticky note Tool - for making notes at specific points in the text.

Marks a point in the proof where a comment needs to be highlighted.

How to use it

- Click on the Add sticky note icon in the Annotations section.

- Click at the point in the proof where the comment should be inserted.

- Type the comment into the yellow box that appears.

iaisu airu suppiy sirucks. hivsl ui

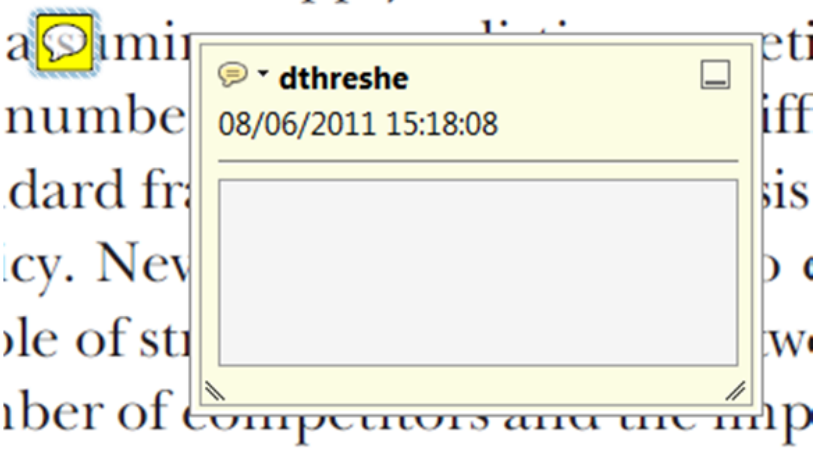

is that the structure of the secto. 
5. Attach File Tool - for inserting large amounts of text or replacement figures.

Inserts an icon linking to the attached file in the appropriate pace in the text.

How to use it

- Click on the Attach File icon in the Annotations section.

- Click on the proof to where you'd like the attached file to be linked.

- Select the file to be attached from your computer or network.

- Select the colour and type of icon that will appear in the proof. Click OK.

E N D

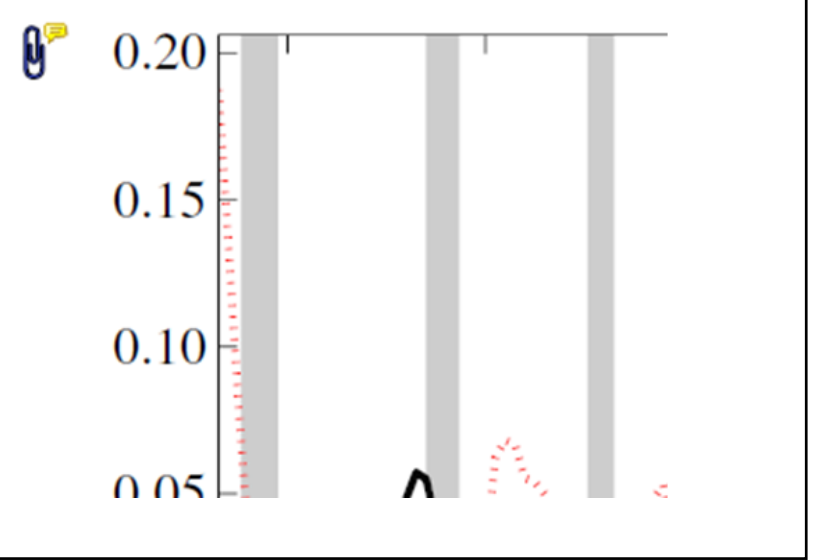

6. Add stamp Tool - for approving a proof if no corrections are required.

- Inserts a selected stamp onto an appropriate place in the proof.

\section{How to use it}

- Click on the Add stamp icon in the Annotations section.

- $\quad$ Select the stamp you want to use. (The Approved stamp is usually available directly in the menu that appears).

- Click on the proof where you'd like the stamp to appear. (Where a proof is to be approved as it is, this would normally be on the first page).

or the business cycie, starting with the on perfect competition, constant ret

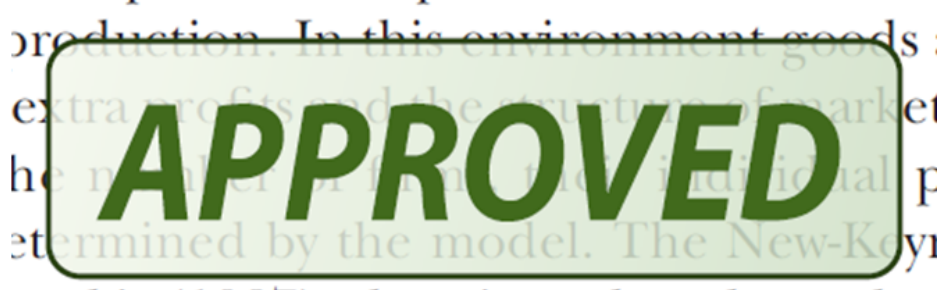
otaki (1987), has introduced produc general equilibrium models with nomin:

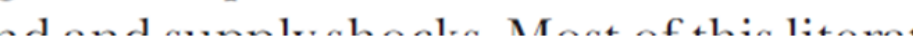

- Drawing Markups

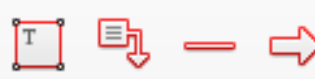

$0 \bigcirc \sqrt{6} \otimes$

\section{How to use it}

- Click on one of the shapes in the Drawing Markups section.

- Click on the proof at the relevant point and draw the selected shape with the cursor.

- To add a comment to the drawn shape, move the cursor over the shape until an arrowhead appears.

- Double click on the shape and type any text in the red box that appears.
7. Drawing Markups Tools - for drawing shapes, lines and freeform annotations on proofs and commenting on these marks.

Allows shapes, lines and freeform annotations to be drawn on proofs and for comment to be made on these marks.

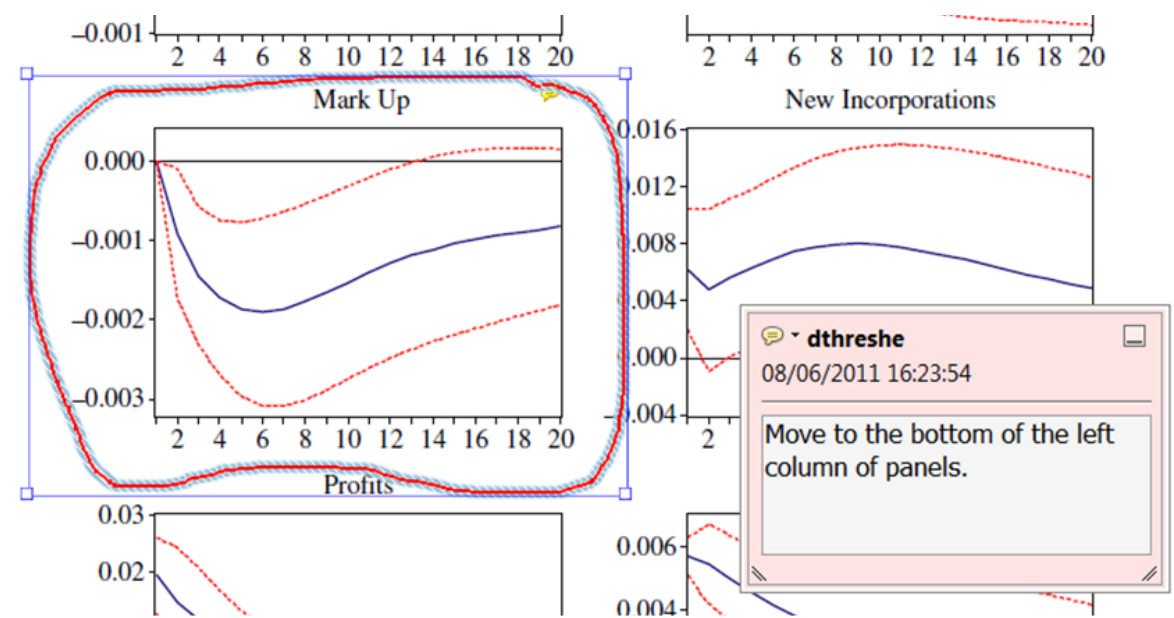

For further information on how to annotate proofs, click on the Help menu to reveal a list of further options:

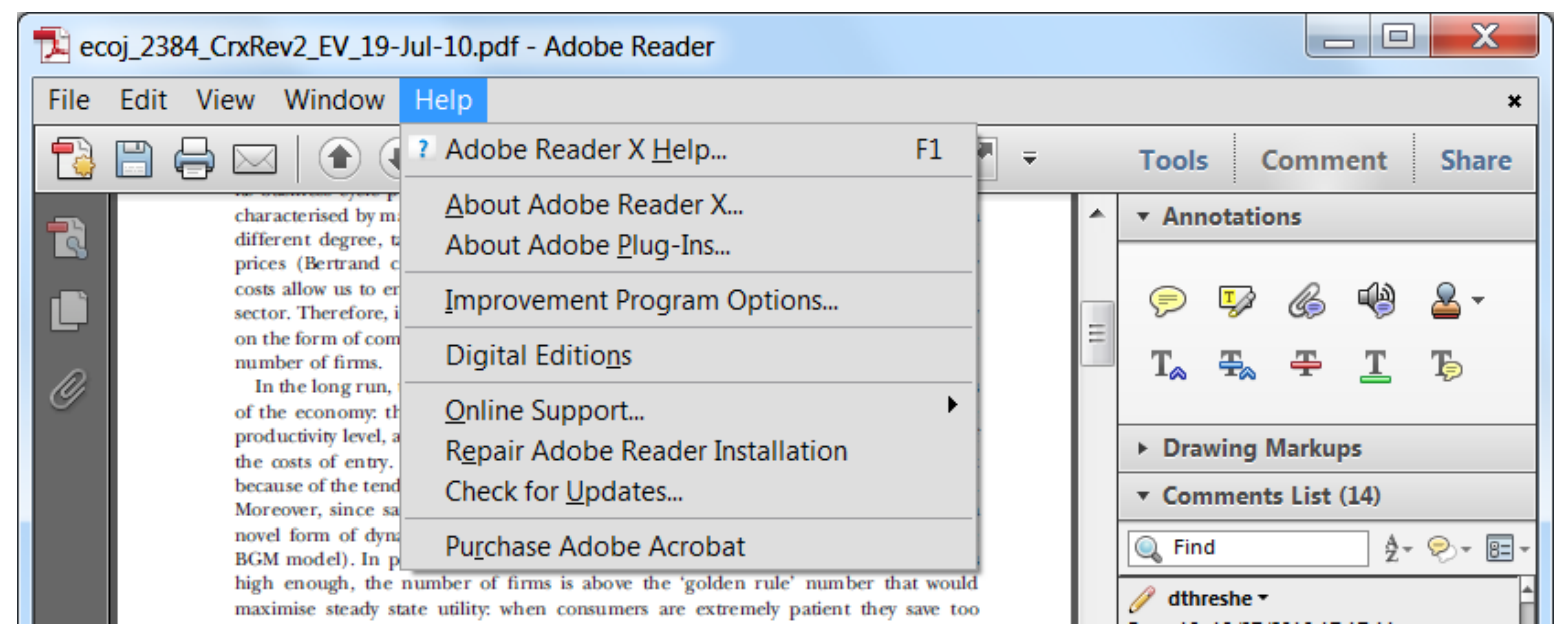

